\title{
Prevalence and Morphometric Evaluation of Cystic Ovaries in Pigs Slaughtered in Tacloban City Abattoir, Philippines
}

\author{
Rio G Macapanas and Santiago T Peña Jr* \\ College of Veterinary Medicine, Visayas State University, Baybay City, Leyte, Philippines \\ *Corresponding author: santiago.penajr@ vsu.edu.ph
}

\begin{abstract}
Article History: 20-077 Received: 25-Mar-20 $\quad$ Revised: 18-Aug-20 $\quad$ Accepted: 30-Sep-20
ABSTRA CT

Cystic ovaries could possibly be either a cause or effect of an existing reproductive disorder as influenced by many factors including hormonal, genetic and the environment. Cystic sows can be a salient source of subfertility in the herd while severely affecting farrowing rates and thus profitability in pig operations. Using direct morphological and morphometric examination of 822 ovaries from either pre-pubertal (about 4 months) or post-pubertal (about 1-2 years) pigs slaughtered at Tacloban City abattoir, this study aimed to determine the prevalence and characterize cystic ovaries which can be used as baseline information for further research relevant to polycystic ovarian syndrome and how it affects the pig's productivity. With the majority of ovaries examined coming from pre-pubertal pigs, our study found a very low prevalence $(-0.85 \%)$ of cystic ovaries and can be attributed principally to post-pubertal pigs divided between oligocystic $(0.61 \%)$ and polycystic ovaries $(0.24 \%)$. As expected, cystic ovaries were much bigger across all dimensions $(\mathrm{P} \leq 0.05)$. Further research should focus on post-pubertal animals particularly those candidates for slaughter due to culling. As sows are likely to perform poorly particularly in the presence of multiple ovarian cysts, skills and technology such as ultrasound for rapid diagnosis is highly required.
\end{abstract}

Key words: Pigs, Cystic ovaries, polycystic ovarian syndrome, Tacloban City, Philippines.

C2020 IJVS - All Rights Reserved

\section{INTRODUCTION}

The percentage of sows not returning to estrus after weaning including but not limited to the development of anovulatory follicular cysts (cystic sows) cannot be taken lightly. These sows become candidates for culling or require additional cost for treatment in an attempt to induce them back to estrus (Geisert et al. 2020). In the broadest sense, this brings a revisit on polycystic ovarian syndrome (PCOS), an important subject of research because of the wide array of factors associated with it spanning from reproductive, metabolic, hereditary, and the environment. It is also the most common endocrine disorder among post pubertal women (Goetsch et al. 2017). In food animals particularly pigs, PCOS becomes more complex due to the absence of pathognomonic signs or very limited clinical diagnosis. The published literature provides an extensive evidence associated in one way or another with PCOS in pigs reported many decades ago signifying the importance of this disease in pig production. Among many others, PCOS has been reported to contribute to 1) the erratic expression of heat and irregular estrous cycle (Cech and
Dolezel 2007; Beek et al. 2011), 2) reduction in farrowing rates where about $10 \%$ of cases of return to estrus in farms is related to cystic sows (Castagna et al. 2004), 3) poor fertility, and 4) culling (Heinonen et al.,1998). Earlier statistics showed that nearly $70 \%$ and close to $15 \%$ of sows with ovarian cysts failed to show signs of estrus or had an irregular estrus, respectively (Ebbert and Bostedt 1993).

In the pig, reports of the incidence of ovarian cysts have been described at about $0.5 \%$ using transcutaneous ultrasonography (Cech and Dolezel 2007) although much earlier studies suggest from $2.4 \%$ (Castagna et al., 2004) to $12 \%$ (Ebbert and Bostedt 1993). Moreover, at 10.5\%, cystic ovaries have been considered as one of the most common post-mortem abnormalities (Tummaruk et al. 2009) among replacement gilts culled due to reproductive failure suggesting that the incidence of ovarian cysts in slaughtered pigs could be associated with poor reproductive performance thus leading to culling.

As proper detection of estrus and regular estrus interval play a crucial role in the reproductive efficiency of the sow, PCOS can pose a salient source of subfertility in the herd while severely affecting farrowing rates and thus

Cite This Article as: Macapanas RG and ST Peña Jr, 2021. Prevalence and morphometric evaluation of cystic ovaries in pigs slaughtered in Tacloban City abattoir, Philippines. International Journal of Veterinary Science 10(1): 59-63. https://doi.org/10.47278/journal.ijvs/2020.026 
profitability in pig operations. This is the first study to determine the prevalence and characterize polycystic ovaries among pigs slaughtered in Tacloban City abattoir, one of the largest abattoirs in Leyte that supplies pork on this most populous city in the region. The prevalence results along with the characterization can serve as baseline information for further research relevant to assisting pig farmers on how PCOS affects the pig's productivity. There is an incessant need to boost pig production in the province considering that the province of Leyte accounts for at least half $(52.4 \%)$ of the swine population in Eastern Visayas region (PSA 2019). Moreover, despite the region's very low swine inventory in the country (3.2\%; PSA 2019), almost $60 \%$ of slaughtered pigs within the Eastern Visayas occurs in Leyte (PSA 2018).

\section{MATERIALS AND METHODS}

\section{Study Site and Collection of Ovaries}

A preliminary survey was initially conducted to determine which abattoir in the Leyte province would likely provide the greatest number of ovaries based on the frequency of their slaughtering activities and the number of animals that are being slaughtered. Given no earlier published reports, at least 384 pigs were required using recommended formula (Martin et al. 1987; Fosgate 2009) at $95 \%$ confidence interval. Ovaries were collected from the Tacloban City abattoir which is one of the biggest abattoirs in Leyte and supports the pork supply of this most populous city in the province. Eventually, 822 ovaries out of 411 slaughtered pigs were collected between January 2019 to May 2019 and examined accordingly based on the parameters described below. This also included about 62 ovaries from 31 pigs collected from Baybay City abattoir about $200 \mathrm{~km}$ away from Tacloban City. A letter requesting to conduct the study was sent to the Mayor of Tacloban City through the City Veterinary Services Office to seek permission and assistance before the study was conducted and following approval by the Student Research Committee of the College of Veterinary Medicine, Visayas State University, Baybay City, Leyte.

Collection of ovaries was done following the abattoir schedule which occurs five times a week except Tuesday and Thursday, from 11:00PM- 06:00AM. Ovaries were collected in a series as pigs become available through the slaughtering line and were classified whether they come from either prepubertal (about 4 months) or post-pubertal pigs (about 1 to 2 years) based on the age records available from the abattoir. Briefly, immediately after evisceration, the ovaries were removed from the reproductive tract using surgical scissors and placed in a glass jar with physiological saline solution $\left(0.9 \% \mathrm{NaCl} ; 28^{\circ} \mathrm{C}\right)$. The ovaries were examined directly within the abattoir and immediately after collection for the presence of cysts.

\section{Morphological and Morphometric Evaluation of Cystic Ovaries}

Morphological examination of cystic ovaries was quite a simple technique after a preliminary examination was conducted to determine between normal and abnormal (cystic) ovaries. However, for consistency with previous reports, cystic ovaries were classified based on the procedures described previously (Nalbandov 1952; Ebbert and Bostedt 1993). Briefly, cystic ovaries were categorized as oligocystic or polycystic and unilateral or bilateral. Ovaries with up to 10 cysts are considered oligocystic and polycystic when the number of cysts is more than 10. When cysts only occur on one side (either right or left ovary), it is unilateral and bilateral when both ovaries are affected. Additionally, follicular fluid was also aspirated using either a $1 \mathrm{~mL}$ or $3 \mathrm{~mL}$ syringe and was assessed for color differences (Ebbert and Bostedt 1993). Morphometric measurements for the length, width, and height of the ovaries were carried out using a Vernier caliper in millimeters, and the size was calculated as the average of the three measurements. For simplicity, length refers to the measurement of both ends or the long side of the ovary which usually has the longest measurement, width refers to how wide the ovary is from side to side, and the height being how high the ovary is and normally has the shortest measurement.

\section{Data Management and Statistical Analysis}

All data were entered in the Microsoft Excel spreadsheet and analyzed accordingly using the XLSTAT version 2019.1.1 (Addinsoft 2020). Descriptive statistics were generated to make comparison among normal, oligocystic and polycystic ovaries in terms of the age of the animal (pre-pubertal vs post-pubertal), location of the ovary (left or right) and color of the follicular fluid. A nonparametric test using Kruskal-Wallis followed by MannWhitney test was used to differentiate between the length, height, weight and size of ovaries. Significant difference was set at $\mathrm{P} \leq 0.05$.

\section{RESULTS}

Our study found a fairly low prevalence $(-0.85 \%)$ of cystic ovaries from pigs slaughtered in Tacloban City (Fig. 1; Table 1). This is attributed principally to post-pubertal pigs and divided between oligocystic (0.61\%) and polycystic ovaries $(0.24 \%)$. Cystic ovaries were fairly distributed between the left and the right although, we didn't find any incidence where the left ovary had more than 10 cysts (polycystic). Apparently, follicular fluid in normal ovaries was clear while yellowish or blood-tinged in cystic ovaries.

As expected, cystic ovaries regardless of the number of cysts present in ovaries were much bigger across all dimensions $(\mathrm{P} \leq 0.05)$. The size which was calculated as the average calculation between the length, width and height ranges from $19.84 \pm 0.11 \mathrm{~mm}$ in normal to $38.53 \pm 6.23 \mathrm{~mm}$ in polycystic ovaries (Fig. 2). All 62 ovaries from 31 pigs collected earlier from Baybay City abattoir were classified normal.

\section{DISCUSSION}

The importance of cystic ovaries in pigs may have been understated considering many factors. Among these may include clinically inapparent signs (Beek et al. 2011) lacking notable changes in specific blood hormone levels (Szulańczyk-Mencel et al. 2010), and perhaps the difficulty of definitive diagnosis of cystic ovaries outside of physical examination of ovaries from slaughtered animals and/or the use of an ultrasound. 
Int J Vet Sci, 2021, 10(1): 59-63.

Table 1: Prevalence of cystic ovaries in pigs slaughtered in Tacloban City abattoir according to age, location and follicular fluid characteristics

\begin{tabular}{|c|c|c|c|c|c|c|c|c|c|c|c|c|c|c|c|c|}
\hline & \multirow{3}{*}{$\begin{array}{l}\text { Number of } \\
\text { Ovaries }\end{array}$} & \multirow{3}{*}{$\begin{array}{l}\text { Percent from } \\
\text { Total }(\%)\end{array}$} & \multicolumn{4}{|c|}{ Age** } & \multicolumn{4}{|c|}{ Ovary Location** } & \multicolumn{6}{|c|}{ Follicular Fluid** } \\
\hline & & & \multicolumn{2}{|c|}{ Pre-Pubertal } & \multicolumn{2}{|c|}{ Post-Pubertal } & \multicolumn{2}{|c|}{ Right } & \multicolumn{2}{|c|}{ Left } & \multicolumn{2}{|c|}{ Clear } & \multicolumn{2}{|c|}{ Yellowish } & \multicolumn{2}{|c|}{ Blood-tinged } \\
\hline & & & (n) & $(\%)$ & (n) & $(\%)$ & (n) & $(\%)$ & $(\mathrm{n})$ & $(\%)$ & $(\mathrm{n})$ & $(\%)$ & $(\mathrm{n})$ & $(\%)$ & $(\mathrm{n})$ & $(\%)$ \\
\hline Nor & 8 & & 766 & 93.1 & 49 & 5.96 & 407 & 49.52 & 408 & 49.64 & 815 & 99.15 & 0 & 0 & 0 & 0 \\
\hline Olig & 5 & & 0 & 0 & 5 & 0. & 2 & 0.24 & 3 & 0.36 & 0 & 0 & 3 & 0.36 & 2 & 0.2 \\
\hline Polyc & 2 & 0.2 & 0 & 0 & 2 & 0.24 & 2 & 0.24 & 0 & 0 & 0 & 0 & 2 & 0.24 & 0 & 0 \\
\hline Total* & 822 & 100 & 766 & 93.19 & 56 & 6.81 & 411 & 50.00 & 411 & 50.00 & 815 & 99.15 & 5 & 0.61 & 2 & 0.24 \\
\hline
\end{tabular}

*Total number of animals examined $(\mathrm{n}=411)$. $* *$ Number and percentage of ovaries in relation to age, location and follicular fluid in total number of ovaries examined $(\mathrm{n}=822)$.
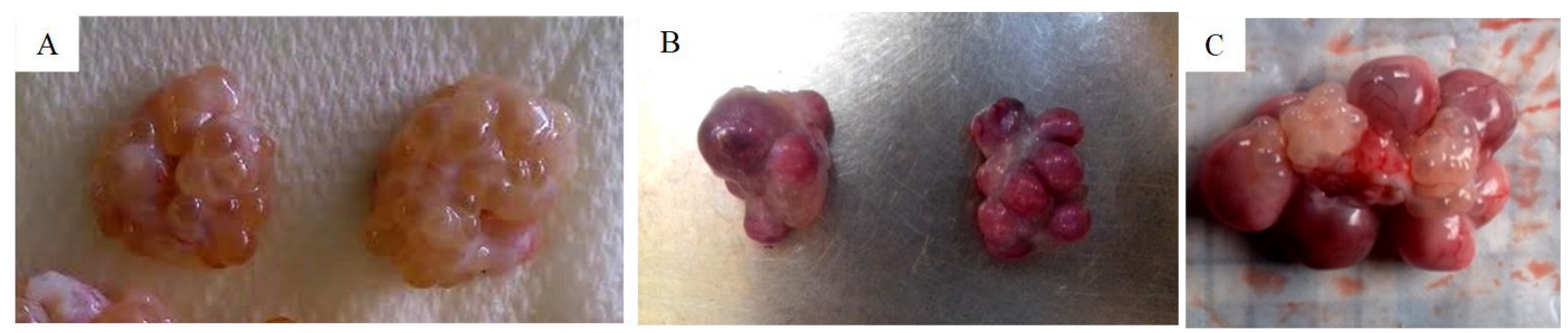

Fig. 1: Normal gilt ovaries (A) and typical ovaries with multiple cysts in various stages either with CL (B) or simple anovulatory follicles (C).

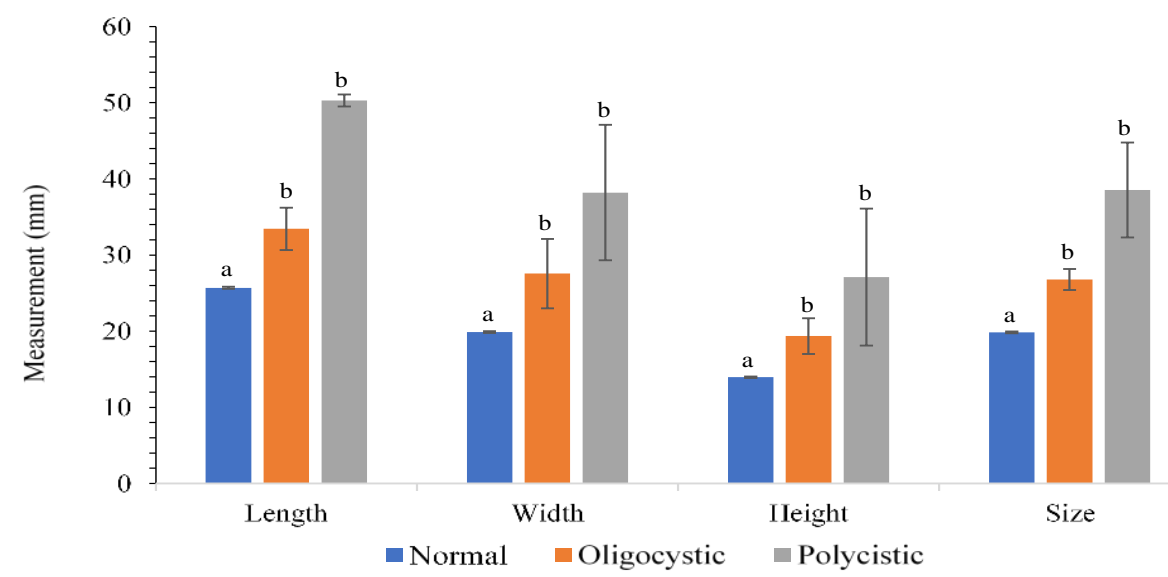

Fig. 2: Mean \pm SEM morphometric measurements among normal, oligocystic and polycystic ovaries.
Our study was an attempt to broadly understand the situation in our region in order to pave way to more specific research undertakings in the future to better understand the incidence and impact of cystic ovaries primarily PCOS on pig production. On the outset, given a good number of ovaries examined, the relatively low prevalence reported in this study and the zero incidence of cystic ovary in prepubertal pig samples should direct future studies on post pubertal pigs. In particular, sows that have been culled and sent for slaughter could be the ideal subjects as well as sows of poor reproductive performance should also be considered. Apparently, the presence of developing CL should also be factored to differentiate from overtly abnormal cystic ovaries and thus the clinical diagnosis.

In diagnosing the incidence of cystic ovaries, heat stress among other stressful conditions encountered by pigs during elevated temperatures in tropical regions like the Philippines are some of primary considerations. It was found that daily exposure of three hours to about $32^{\circ} \mathrm{C}$ during the follicular phase of the estrous cycle could lead to increased levels of progesterone and total glucocorticoids which could potentially predispose sows to ovarian cyst formation (Scholten and Liptrap 1978). In fact, corticoid levels had been shown to increase during stressful events in the case of surgery or illness during the active phase of follicular development leading to delayed estrus (Hennessy and Williamson 1983). Summer heat stress has been distinctly identified factor associated with reduced reproductive performance and infertility among pigs (Peña et al. 2017) and even cows (García-Ispierto et al. 2007). Apparently, reduction in preovulatory luteinizing hormone (LH), the principal hormone involved in normal ovulation, which could be possible due to stress associated with truck transport (Dobson 1987) has been implicated in ovarian cyst formation (Castagna et al. 2004). Experimentally, cortisol has been demonstrated to suppress pulsatile LH secretion in the ovariectomized ewes through the inhibition of pituitary responsiveness to GnRH (Breen and Karsch 2004). This should therefore be considered in the housing management and routine handling of sows particularly in tropical countries and in intensive pig production systems.

Generally, ovarian cysts distinctly look larger reaching as far as 50mm using ultrasonography (Knox and Althouse 1999) although an earlier study reported a diameter between $21 \mathrm{~mm}$ to $45 \mathrm{~mm}$ for those enlarged follicles (McGaughey 1975). The significant increase in the size of the cystic ovaries as observed in this study is something to be expected. Unfortunately, the limited number of post 
pubertal pigs along the course of collection period has precluded our study to compare between normal and cystic ovaries for this group of animals. However, it was quite simple to easily identify a cystic ovary regardless of the age of the animal given its gross appearance, the consistency among ovarian follicles, and the presence of persistent CL enclosed in the follicular wall, among others. Some good examples of normal and cystic ovaries can be found in the literature (Cech and Dolezel 2007; Grabowska et al. 2016) which have been referenced in this study along with the preliminary actual examination of ovaries in the abattoir. Nevertheless, the degree of luteinization for those ovarian cysts with persistent CL may vary even within the same ovary. Moreover, while the color of the follicular fluid grossly differs between normal and cystic ovaries as described, this study also confirms the earlier reports where some cyst may contain blood in it (reviewed by Ebbert and Bostedt 1993). This case could be normally observed after the collapse of a normal follicle (Nalbandov 1952) or a case of an even much complicated reproductive disorder and should be a subject of future investigations.

The absence of a good historical background of the reproductive performance of those sows identified with ovarian cysts in this study precludes the possibility to do correlation studies to better understand the impact of cystic ovaries against those sows. Unfortunately, this is a common reality in provincial abattoirs and pig farmers particularly those engaged in smallholder or backyard pig production may have a number of reasons of sending their sows for slaughter. The study of Szulañczyk-Mencel et al. (2010) however, distinctly presents that polycystic ovaries (more than 10 ovarian cysts) greatly impact these animals to normally develop physiological ovarian follicles required for normal pig production. Additionally, there is this higher likelihood for all stages of ovarian follicles to degenerate in effect.

Formation of ovarian cysts may be due to a wide variety of factors from hormonal imbalance, stress, toxins, and a host of identified and unknown risk factors (Beek et al. 2011). As steroid levels appear to be almost always mentioned, the recent study of Costermans et al. (2019) is something worth to consider. The study has found some empirical evidence showing that steroid levels of follicular fluid differs from that of the serum and thus should be highly considered in clinical diagnosis particularly in the first half of the follicular phase of the estrous cycle in sows. Due to logistical issues, steroid levels both from serum and follicular fluid were not determined in the present study.

\section{Conclusion}

In conclusion, the prevalence of cystic ovaries in prepubertal animals was zero as demonstrated in this study and thus research interest on ovarian cyst formation and its impact on pig reproduction should focus on post-pubertal animals particularly those candidates for slaughter due to culling. Regardless of the number of cysts present, the size of cystic ovary is grossly enlarged compared to normal ones, but this might need to be considered when examining a large number of positive animal samples. As sows are likely to perform poorly particularly in the presence of multiple ovarian cysts, it is also encouraged among field veterinarians to develop skills in rapid diagnosis of cystic ovaries, like the use of real-time ultrasound, so as not to waste time waiting confirmation after slaughter before decisions for culling are to be made.

\section{Acknowledgement}

The authors thankfully acknowledge the support of the local government units of Tacloban City and the City of Baybay, Leyte through the Office of the City Mayor and City Veterinary Services Office, Mr. R. Macapanas for the long nights during the collection of ovaries, and the Visayas State University for the financial assistance in publication. This study is part of the thesis work (Macapanas 2020) dedicated to pig growers in the region.

\section{REFERENCES}

Addinsoft, 2020. XLSTAT Statistical and Data Analysis Solution. Available at https://www.xlstat.com. Boston, USA.

Beek J, Jong E, Soom A, de Kruif A and Maes D, 2011. Ovarian cysts in sows: a multifactorial disorder with consequences on the reproductive performance. Vlaams Diergeneeskd Tijdschr 80: 215-222.

Breen KM and Karsch FJ, 2004. Does cortisol inhibit pulsatile luteinizing hormone secretion at the hypothalamic or pituitary level? Endocrinology 145: 692-698. https://doi.org/ 10.1210/en.2003-1114

Castagna CD, Peixoto $\mathrm{CH}$ and Bortolozzo FP, 2004. Ovarian cysts and their consequences on the reproductive performance of swine herds. Animal Reproduction Science 81: 115-123. https://doi.org/10.1016/j.anireprosci.2003.08. $\underline{004}$

Cech S and Dolezel R, 2007. Treatment of ovarian cysts in sowsa field trial. Veterinarni Medicina (Praha) 52: 413.

Costermans NGJ, Soede NM and Blokland M, 2019. Steroid profile of porcine follicular fluid and blood serum: relation with follicular development. Physiological Reports 7: e14320. https://doi.org/10.14814/phy2.14320

Dobson H, 1987. Effect of transport stress on luteinizing hormone released by GNRH in dairy cows. European Journal of Endocrinology 115: 63-66.

Ebbert W and Bostedt H, 1993. Cystic degeneration in porcine ovaries-first communication: morphology of cystic ovaries, interpretation of the results. Reproduction in Domestic Animals 28: 441-450. https://doi.org/10.1111/j.1439 0531.1993.tb01021.x

Fosgate GT, 2009. Practical sample size calculations for surveillance and diagnostic investigations. Journal of Veterinary Diagnostic Investigation 21: 3-14.

García-Ispierto I, F López-Gatius, G Bech-Sabat, P Santolaria, J Yániz, C Nogareda, F De Rensis, and M López-Béjar, 2007. Climate factors affecting conception rate of high producing dairy cows in northeastern Spain. Theriogenology 67: 13791385. https://doi.org/10.1016/j.theriogenology.2007.02.009

Geisert RD, P Sutvosky, MC Lucy, FF Bartol and AE Meyer, 2020. Chapter 15-Reproductive Physiology of Swine, In Bazer FW, Lamb GC and Wu G (ed), Animal Agriculture. Academic Press.

Goetsch AL, Kimelman D and Woodruff TK, 2017. Polycystic Ovary Syndrome, In: Fertility Preservation and Restoration for Patients with Complex Medical Conditions, Springer International Publishing AG.

Grabowska R, B Blaszczyk, T Stankiewicz, T Banas, S Hale, and J Udala, 2016. Quality of oocytes in prepubertal and pubertal swine. Turkish Journal of Veterinary and Animal Sciences, 40: 89-94.

Heinonen M, Leppävuori A and Pyörälä S, 1998. Evaluation of reproductive failure of female pigs based on slaughterhouse material and herd record survey. Animal Reproduction 
Int J Vet Sci, 2021, 10(1): 59-63.

Science 52: 235-244. https://doi.org/10.1016/S0378-4320 (98)00105-5

Hennessy D and Williamson P, 1983. The effects of stress and of ACTH administration in hormone profiles, oestrus and ovulation in pigs. Theriogenology 20: 13-26. https://doi.org/10.1016/0093-691X(83)90019-5

Knox RV and Althouse GC, 1999. Visualizing the reproductive tract of the female pig usingreal-time ultrasonography. Journal of Swine Health Production 7: 207-215.

Macapanas R, 2020. Prevalence and characterization of plycystic ovaries in pigs slaughtered in selected abattoirs in Leyte. College of Veterinary Medicine, Visayas State University (Undergraduate Thesis).

Martin SW, Meek AH and Willeberg P, 1987. Veterinary Epidemiology: Principles and Methods, Iowa State University Press, Ames IA.

McGaughey RW, 1975. A comparison of the fluids from small and large ovarian follicles of the pig. Biological Reproduction 13: 147-153.

Nalbandov A, 1952. Anatomic and endocrine causes of sterility in female swine. Fertility and Sterility 3: 100-120.

Peña ST Jr., B Gummow, AJ Parker, and DBBP Paris, 2017. Revisiting summer infertility in the pig: Could heat stressinduced sperm DNA damage negatively affect early embryo development? Animal Production Science, 57: 1975-1983. https://doi.org/10.1071/AN16079
PSA, 2018 Livestock and poultry statistics of the Philippines (2013-2017). Philippines Statistics Authority (PSA), Quezon City, Philippines. Available at https://psa.gov.ph/ sites/default/files/livestock.\%20AND\%20POULTRY\%20S TATISTICS $\% 20$ of $\% 20$ the $\% 20$ PHILIPPINES $\% 20$ as $\% 20$ of \%2006\%20Mar\%202019_V4_0.pdf. [Accessed: December $3,2019]$.

PSA, 2019. Swine production in Eastern Visayas increases by 2.2 percent. Philippine Statistics Authority (PSA), Region VIIIEastern Visayas. Available at http://rsso08.psa.gov. $\mathrm{ph} /$ article/swine-production-eastern-visayas-increases-22 percent\#sthash. vEhI70rE.76EYws1O.dpbs.

Scholten J and Liptrap R, 1978. A role for the adrenal cortex in the onset of cystic ovarian follicles in the sow. Canadian Journal of Comparative Medicine 42: 525.

Szulańczyk-Mencel K, Rzasa A and Bielas W, 2010. Relationships between ovarian cysts and morphological and hormonal state of ovarian cortex in sows. Animal Reproduction Science 121: 273-278. https://doi.org/ 10.1016/i.anireprosci.2010.06.001

Tummaruk P, Kesdangsakonwut S and Kunavongkrit A, 2009. Relationships among specific reasons for culling, reproductive data, and gross morphology of the genital tracts in gilts culled due to reproductive failure in Thailand. Theriogenology 71: 369-375. https://doi.org/10.1016/ j.theriogenology.2008.08.003 